\title{
DISECCION ESPONTANEA DE LA ARTERIA MESENTERICA SUPERIOR
}

\author{
Drs. Luis Muse R.(1), Andrés $O^{\prime}$ Brien S, Soledad Loyola Z, Francisco Cruz O.
}

Departamento de Radiología del Hospital Clínico de la Pontificia Universidad Católica de Chile.

1. Residente.

Abstract: Superior mesenteric artery spontaneous disection is a very rare condition. The pathogenesis is not clear yet. It is believed to be caused by cystic necrosis of the media, fibromuscular displasia, abdominal trauma, arterial hypertension, and atherosclerosis.

The form of presentation of this disease is manifested as abdominal pain or hypovolemic shock, secondary to rupture of the dissected artery.

Althorugh the gold standard diagnosis is angiography, definitive diagnosis can be made by Computed Tomography.

This is a case report of a 45 year old male who came to the Urgency Service because of acute abdominal pain. CT scan was read as SMA dissection.

Key words: Mesenteric artery, CT.

Resumen: La disección espontánea de la arteria mesentérica superior es una condición muy poco frecuente. Su etiopatogenia es aún desconocida. Se postula como causa entre otras necrosis quística de la túnica media, displasia fibromuscular, trauma abdominal cerrado, hipertensión arterial y ateroesclerosis.

Su forma de presentación en la mayoría de los casos corresponde a dolor abdominal intenso o shock hipovolémico secundario a rotura de la arteria disecada.

El método diagnóstico de mayor rendimiento es la angiografía, la que además permite efectuar procedimientos terapéuticos. En muchos casos, sin embargo se puede realizar un diagnóstico definitivo mediante tomografía computada (angioTac), que permite obtener contraste adecuado a nivel de la arteria mesentérica superior.

Se presenta el caso de un paciente de sexo masculino, 45 años, que ingresa al Servicio de Urgencia por un cuadro de dolor abdominal difuso. Se realiza una tomografía axial computada (TAC) demostrando este diagnóstico.

Palabras claves: Arteria mesentérica, TAC.

Muse L. y cols. Disección espontánea de la arteria mesentérica superior. Rev Chil Radiol 2002; 8: 133 - 134. Correspondencia: Dr. Luis Muse R. Departamento de Radiología del Hospital Clínico de la Pontificia Universidad Católica de Chile. Marcoleta 367 - Santiago.

\section{Historia Clínica}

Paciente de sexo masculino, 45 años, sin antecedentes mórbidos, que se presenta al servicio de urgencia con un cuadro de dolor abdominal difuso permanente de tres días de evolución. Al examen físico, no se demostraron signos de irritación peritoneal. Se realizan exámenes generales de laboratorio y una TAC de abdomen y pelvis, con medio de contraste oral y endovenoso.

La TAC (Figuras 1a-e) evidenció engrosamiento asimétrico de la pared en la arteria mesentérica superior, el cual comprimía el lumen contrastado, adoptando una configuración espiroidea hacia distal. Algunas asas de intestino delgado presentaban engrosamiento focal de sus paredes. No existían signos de perforación intestinal ni líquido peritoneal. El diagnóstico fue confirmado con angiografía.
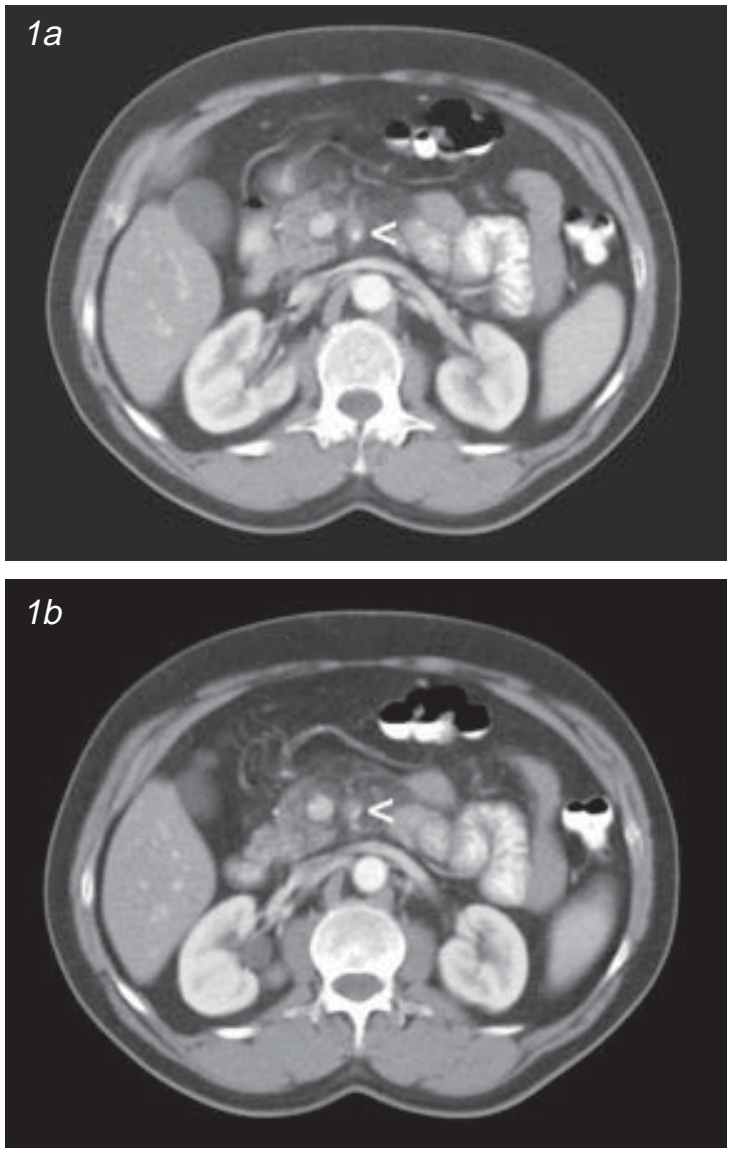

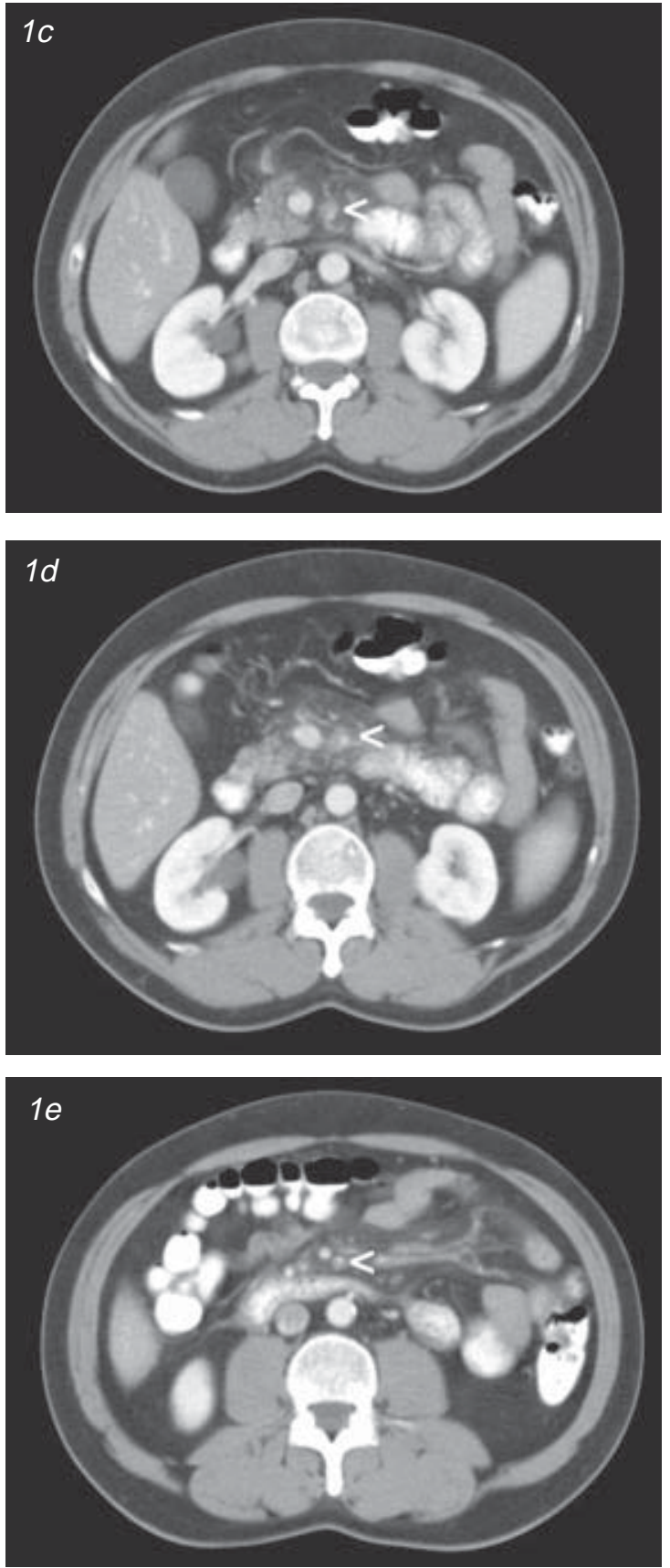

Figuras a-e. Punta de flecha indicando la arteria mesentérica superior.

\section{Discusión}

La disección espontánea de la arteria mesentérica superior es una condición muy poco frecuente. El primer caso fue descrito por Bauersfeld en 1947 en una mujer de 87 años, que falleció debido al infarto intestinal producido.

La etiología y la patogenia de la disección espontánea de la arteria mesentérica superior (AMS) son desconocidas. Algunos investigadores han indicado que estaría en relación con una necrosis quística de la túnica media, displasia fibromuscular, trauma abdominal cerrado, hipertensión arterial y ateroesclerosis.
Clínicamente, los pacientes se presentan de dos maneras en la mayoría de los casos:

a) con dolor abdominal isquémico, producido por compresión del lumen verdadero por el lumen falso en arteria mesentérica.

b) con shock hipovolémico, debido a la rotura hacia fuera de la arteria disecada.

La disección generalmente comienza cerca del origen de la AMS, 1,5 a $3 \mathrm{~cm}$. Este segmento corresponde a la porción retropancreática, que es fija, lo que la haría más susceptible a fuerzas de tracción. En el presente caso, la disección comenzó aproximadamente a $2 \mathrm{~cm}$.

En muchos casos se puede realizar un diagnóstico definitivo con técnicas de estudio por imágenes no invasivas como la tomografía computada helicoidal en fase arterial (angioTAC), la que permite obtener un contraste adecuado a nivel de las ramas principales de la aorta abdominal, pudiendo identificar en algunos casos el flap de disección. Además, es posible evaluar las asas intestinales, signos isquémicos y otras complicaciones como perforación intestinal, lo que es de gran importancia para decidir el manejo terapéutico.

El otro método diagnóstico, considerado el estándar es la angiografía. Esta es superior al angioTAC en la evaluación de las arterias de menor calibre, es decir en este caso, las ramas mesentéricas y la relación de éstas con el flap de disección.

La angiografía por cateterismo permite efectuar procedimientos terapéuticos, en este caso, reparación de la zona de disección mediante instalación de stents.

El paciente fue manejado médicamente con terapia anticoagulante endovenosa, dada su condición estable, con buena evolución clínica, siendo dado de alta con tratamiento anticoagulante oral, indicando control a los 6 meses con angioTAC.

\section{Bibliografia}

1. Sheldon PJ, Esther JB, Sheldon EL, Sparks SR, Brophy DP, Oglevie SB. Spontaneous dissection of the superior mesenteric artery. Cardiovasc Intervent Radiol 2001;24:329-31.

2. Barmeir E, Halachmi S, Croitoru S, Torem S. CT angiography diagnosis of spontaneous dissection of the superior mesenteric artery. AJR Am J Roentgenol 1998;171:1429-30.

3. Hyodoh H, Hyodoh K, Takahashi K, Yamagata M, Kanazawa K. Three-dimensional CT imaging of an isolated dissecting aneurysm of the superior mesenteric artery.. Abdom Imaging 1996;21:515-6.

4. Sparks SR, Vasquez JC, Bergan JJ, Owens EL. Failure of nonoperative management of isolated superior mesenteric artery dissection. Ann Vasc Surg 2000;14:105-9.

5. Vignati PV, Welch JP, Ellison L, Cohen JL. Acute mesenteric ischemia caused by isolated superior mesenteric artery dissection. J Vasc Surg 1992;16: 109-12. 